\title{
Propagation and effects of a mesoscale gravity-wave over a weakly-stratified nocturnal boundary layer during SABLES2006 field campaign
}

\author{
S. Viana, C. Yagüe and G. Maqueda
}

Received: date / Accepted: date

\begin{abstract}
During SABLES2006 (Stable Atmospheric Boundary Layer Experiment in Spain 2006) field campaign, a gravity-wave episode was observed on the night of July 11 by the microbarometers deployed on the surface and on the 100-m tower. The high-amplitude, low-frequency periodic pressure fluctuations were very well correlated with the windspeed and direction. Data from neighbouring automatic stations showed that the gravity wave was not local, but long-lived and mesoscale. The propagation of the wave over the experimental site had significant effects on the structure of the weakly-stratified nocturnal boundary layer developed that night: the stability increased, turbulent vertical motions were suppressed, the nocturnal low-level jet was disrupted, and periodic temperature fluctuations of amplitude up to 3-4 K were observed. In this work we analyse the different available data sources (tower data, RASS-SODAR, microbarometers, satellite imagery, automatic stations) to describe the phenomena in depth and to find a suitable explanation for the generation and propagation of the wave. The linear wave theory explains remarkably well most of the observations, and the wave parameters could be estimated by applying a wavelet-based technique to surface microbarometers measurements. We also analyse the vertical structure of the wave and find wave ducting conditions above the surface. Finally, by means of the multiresolution flux decomposition, we analyse in detail the changes in vertical turbulent fluxes

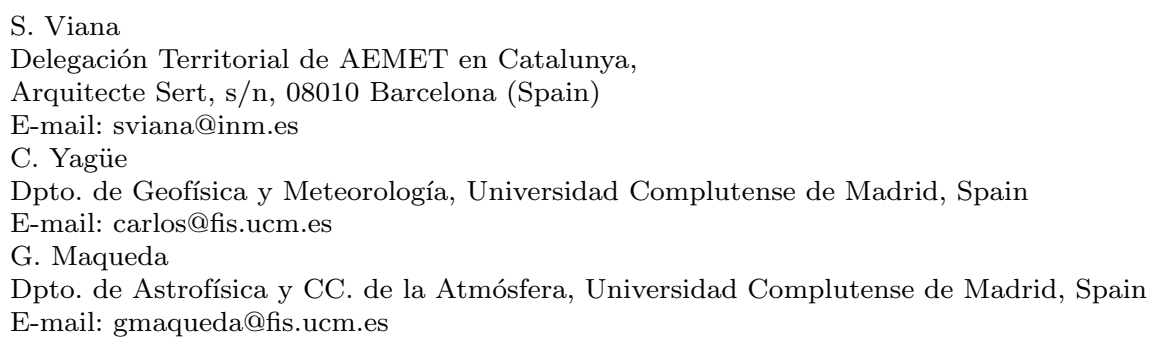


and the spectra of turbulent motions produced by the interaction between the gravity wave and the local flow.

Keywords Mesoscale gravity wave - Nocturnal boundary layer - Wave ducting $\cdot$ Wave-turbulence interactions

\section{Introduction}

Gravity waves are one of the most common phenomena observed in atmospheric studies of all kinds. Their importance as a source for energy and momentum transport in the atmosphere is being increasingly recognized. Atmospheric processes with a wide range of scales, from synoptic-scale to microscale, may be affected by the propagation of these waves, due to their extensive range of periods, wavelengths and phase speeds, and the amount of energy and momentum involved, which is eventually dumped into the mean flow (Nappo, 2002) or dissipated in the form of turbulence (Einaudi and Finnigan, 1993; Smedman et al., 1995) which enhances intermittent turbulent transport in the atmospheric boundary layer (ABL), especially if these waves become unstable and break. The general framework for the study of gravity waves is the linear wave theory, and the Taylor-Goldstein equation is their main governing expression (Gossard and Hooke, 1975; Lindzen and Tung, 1976). This theory results from the linearization of the primitive set of equations for an inviscid, non-rotating fluid. The polarization relations derived from this theory predict certain phase relationships between windspeed components, temperature, pressure and air density, which have classically been sought in field data as evidences of gravity-wave activity.

Most papers dealing with gravity waves study their effects on atmospheric processes with scales similar to those of the observed waves. For instance, large-scale gravity waves with long wavelengths and periods, which propagate horizontally hundreds or thousands of kilometres, are usually studied with a synoptic or mesoscale approach, focusing on their interaction with clouds and precipitation (Koch and O'Handley, 1997) or damaging winds (Bosart and Cussen, 1973; Pecnick and Young, 1984). These waves are typically produced by favourable large-scale atmospheric patterns (Uccellini and Koch, 1987), mesoscale convective activity (Böhme et al., 2004) or developing thunderstorms (Uccellini, 1975), and typically propagate over layers located well above the ground. Gravity waves with smaller scales appear frequently in stablystratified layers of the atmosphere; among these, those produced close to the surface in the lower atmosphere, during night-time in the nocturnal boundary layer (NBL) or in long-lived stable boundary layers (SBLs) in polar regions, have been thoroughly studied from a micrometeorological point of view (King et al., 1987; Rees et al., 2001; Sun et al., 2003). One of the key points is the interaction between the mean flow, waves and turbulence (Chimonas, 1999), and the intermittent nature of the latter in the presence of waves. Many papers have been published dealing with these issues from a variety of different approaches. Einaudi and Finnigan addressed the wave-turbulence coupling in 
a series of papers published during the 80s and early 90s (see Einaudi and Finnigan 1993 and references therein). Nappo (2008) studied the effects of an internal wave following a pressure jump on plume dispersion. Wave-induced turbulent diffusion by wave breaking or Kelvin-Helmholtz shear instability (K-H instability) was studied in Sun et al. (2003) and Cheng et al. (2005). However, most of the links between turbulence and waves are still poorly understood, and a generalized theory regarding turbulent mixing in the presence of periodic atmospheric disturbances, if it exists, is far from being formulated. On the other hand, relatively few studies have been concerned with the local effects produced by the propagation of a large scale gravity wave along a specific site. Even when the wave ducting region where the wave can propagate without attenuation is located far from the ground, surface winds are typically driven by the surface pressure gradients established due to the wave. Thus the wind and wind shear regimes close to the ground can change in response to these periodic pressure disturbances, which can lead to changes in the stratification. As a result, a different turbulent regime emerges, and the contribution to vertical transport by the different turbulent scales can change. The main objective of this work is to study a mesoscale gravity wave event detected during the SABLES2006 field campaign, and to develop a comprehensive analysis of the effects of its propagation close to the surface. A brief description of the experimental site and the data available is made in Section 2. Section 3 explains some of the methods applied to our field data during this study. The main results are drawn in Section 4, and finally, some conclusions are summarized in Section 5.

\section{Data}

The SABLES2006 (Stable Atmospheric Boundary Layer Experiment in Spain 2006) field campaign (Yagüe et al., 2007) took place during June and July 2006 at the Research Centre for the Lower Atmosphere (CIBA in Spanish; $41^{\circ} 49^{\prime} \mathrm{N}$, $4^{\circ} 56^{\prime} \mathrm{W}, 840 \mathrm{~m}$ above sea level). This experimental site is located around 30 $\mathrm{km}$ north-west from Valladolid city, in the northern Iberian plateau, on a region known as Montes Torozos, which forms a high plain of nearly $200 \mathrm{~km}^{2}$ elevated above the plateau (see Fig. 1a). The surrounding terrain is quite flat and homogeneous, consisting mainly of different crop fields and some scattered bushes. The Duero river flows along the south-east border of the high plain, and two small river valleys, which may act as drainage channels in stable conditions, extend from the lower south-west region of the plateau.

The main instrumentation available at CIBA is installed on the 100-m meteorological tower (Table 1), and includes sonic and cup anemometers, platinum resistance thermometers, wind vanes, humidity sensors, etc. Most of these instruments were installed and calibrated in 2001 by the Risoe National Laboratory, when the CIBA's facilities were partially renovated (Conangla et al., 2008), as part of a project to modernize the centre, which has been active 
Table 1 Main instrumentation installed on the 100-m mast and around the site.

\begin{tabular}{|l|l|l|}
\hline Instrument & Altitude $(\mathrm{m})$ & $\begin{array}{l}\text { Sampling } \\
\text { rate (Hz) }\end{array}$ \\
\hline $\begin{array}{l}\text { Metek USA-1 } \\
\text { Sonic anemome- } \\
\text { ters }\end{array}$ & $3-19.6-96.6$ & 20 \\
\hline Wind vanes & $9.6-34.6-74.6-98.6$ & 5 \\
\hline $\begin{array}{l}\text { Cup anemome- } \\
\text { ters }\end{array}$ & $\begin{array}{l}2.3-9.6-34.6-50- \\
74.6-98.6\end{array}$ & 5 \\
\hline $\begin{array}{l}\text { Platinum resis- } \\
\text { tance thermome- } \\
\text { ters }\end{array}$ & $\begin{array}{l}2.3-10.5-20.5- \\
35.5-97.5\end{array}$ & 1 \\
\hline $\begin{array}{l}\text { Tower micro- } \\
\text { barometers }\end{array}$ & $20-50-100$ & 2 \\
\hline $\begin{array}{l}\text { Array micro- } \\
\text { barometers }\end{array}$ & 1.5 & 2 \\
\hline
\end{tabular}

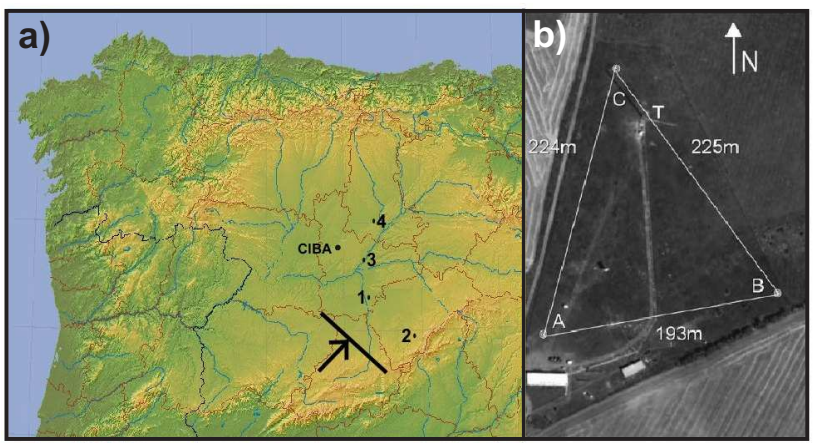

Fig. 1 (a) The position of the CIBA experimental site on the upper Spanish plateau, main topographic features and location of selected automatic stations from the AEMET network. A black line and an arrow mark the wave front and the direction of propagation. (b) Aerial image of the CIBA site, with the location of the 100-m tower $(\mathrm{T})$ and the orientation of the triangular array of microbarometers $(\mathrm{A}, \mathrm{B}, \mathrm{C})$.

since the 80s (San José et al., 1985; Yagüe and Cano, 1994). Table 1 shows a summary of the instruments, levels and sampling rates.

One of the objectives of SABLES2006 was to fill in some gaps detected during previous campaigns (Cuxart et al., 2000), especially regarding the observation of internal gravity waves (IGWs). High resolution microbarometers have become the most commonly used procedure for detecting and studying gravity waves. In this campaign, a total of six PAROSCIENTIFIC microbarometers were deployed: three were installed at 20,50 and $100 \mathrm{~m}$ on the 100-m tower, and the other three were set up at surface level, in a triangular array of approximately $200 \mathrm{~m}$ per side (Fig. 1b). GILL static pressure ports were installed to avoid data contamination by dynamic pressure fluctuations. A more detailed description of the PAROSCIENTIFIC microbarometers is available in Cuxart et al. (2002). 
In addition, data from the RASS-SODAR profiler, operating continuously at CIBA, has been used. It provided wind and temperature data up to 500 $m$ above ground level (AGL), which was essential for the understanding of the vertical structure of the studied gravity wave, since the day of the event was not part of the intensive operational period (19-31 June), when tethered balloon soundings were also available.

\section{Methodology}

3.1 Wavelet transform and derivation of wave characteristics

During recent years, wavelets have become a widespread method for the analysis of geophysical time series. Conceptually equivalent to a sort of local Fourier decomposition, the wavelet transform is a powerful spectral tool for characterizing non-stationary time series in which different temporal scales are present. In the context of the SBL, where intermittent bursts of turbulence (high frequencies) occur, along with longer lasting coherent structures (IGW, K-H instabilities, etc) of lower frequencies, the wavelet transform has been shown in many studies to be very useful to characterize these events (Rees et al., 2001; Terradellas et al., 2001). An increasing number of papers describing the wavelet transform and their applications to geophysical sciences are available (Daubechies, 1992; Farge, 1992; Torrence and Compo, 1998); in this section we discuss in detail only the methodology used to extract the wave parameters from the wavelet transforms of the pressure time series registered by the microbarometers located on the surface array.

The wavelet transform coefficients of a time series $f(t)$ are defined as (Daubechies, 1992):

$$
F(s, \tau)=\int_{-\infty}^{\infty} f(t) \psi_{s \tau}^{*}(t) d t
$$

where $*$ means complex conjugation, $s$ and $\tau$ are the scale (dilatation) and time (translation) parameters, and $\Psi_{\mathrm{s}} \tau(t)$ is the wavelet function for a given scale and time. Functions $\Psi_{\mathrm{s}} \tau(t)$ are generated from a mother wavelet $\Psi(t)$ according to the expression:

$$
\psi_{s, \tau}(t)=\frac{1}{\sqrt{|s|}} \psi\left(\frac{t-\tau}{s}\right)
$$

In this study we have used the Morlet wavelet, (a complex function consisting of a plane wave modulated by a Gaussian), which has a fixed relationship between scales $(s)$ and equivalent Fourier periods $(P)$, and has been widely used for the analysis of geophysical time series (Torrence and Compo, 1998; Cuxart et al., 2002). Wavelet analysis based on complex mother wavelets produces complex coefficients for every instant $t$ and scale $s$, from which the phases $(\varphi)$ can be calculated. Given at least 3 time series of an atmospheric variable measured at different points $\left(x_{i}, y_{i}\right)$ at the surface, when spectral peaks in the 
wavelet transform appear at certain periods $P$ (or associated frequencies $\omega$ ) and time intervals, the phases of the wavelet coefficients inform about the propagation of these coherent structures along the surface array:

$$
\varphi_{i}=k_{x} x_{i}+k_{y} y_{i}-\omega t
$$

Here $\left(k_{x}, k_{y}\right)$ are the components of the horizontal wavenumber vector $\mathbf{k}_{h}$. By solving the system formed by the phase differences (Terradellas et al., 2001):

$$
\begin{aligned}
& \varphi_{2}-\varphi_{1}=k_{x}\left(x_{2}-x_{1}\right)+k_{y}\left(y_{2}-y_{1}\right) \\
& \varphi_{3}-\varphi_{1}=k_{x}\left(x_{3}-x_{1}\right)+k_{y}\left(y_{3}-y_{1}\right)
\end{aligned}
$$

one can deduce the components of $\mathbf{k}_{h}$, from which the rest of the parameters (wavelength $\lambda$, phase velocity $c$, direction of propagation $\alpha$ ) of the wave-like coherent structure may be derived:

$$
\begin{aligned}
& \lambda=2 \pi /\left|\mathbf{k}_{h}\right| \\
& \alpha=\tan ^{-1}\left(k_{y} / k_{x}\right) \\
& c=\lambda / P
\end{aligned}
$$

Before applying this methodology for a given region of high wavelet modulus, it is advisable to apply some kind of significance testing, in order to assign statistical significance to the spectral peak for which the wave parameters will be calculated. The most extended significance tests for wavelets (Torrence and Compo, 1998) compare the power of every point in the time/period space with a background spectrum for the null hypothesis (which is often defined assuming that different realizations of the process are chi-square distributed, or fitting a red noise process to the time series). If the former exceeds the $95 \%$ threshold of the latter, the point is statistically significant. We acknowledge the need for significance testing in the study of weaker gravity wave events from pressure records when other data sources (wind and temperature data from tower levels) are not available or do not support gravity wave behaviour (perhaps because the propagation of the wave is confined to an atmospheric layer well above the tower). However, in this case study, as will be shown later, gravity wave behaviour is sufficiently proved by a number of pieces of supporting evidence from tower and RASS-SODAR data.

\subsection{Multiresolution flux decomposition}

The eddy covariance technique is the most widespread method used to evaluate turbulent fluxes from fast-response instruments like sonic anemometers. For an accurate evaluation of the turbulent fluxes and other derived parameters, the chosen averaging length must be able to properly capture the effects of the turbulent fluctuations, while preventing the inclusion of larger-scale contributions. Ideally, the averaging length should be close to a minimum of energy in the spectrum of the turbulence (the so-called gap), which separates turbulent eddies from larger-scale motions, such as mesoscale flows or wavy structures. 
Under neutral or unstable conditions it is possible to successfully define the averaging length a priori, because the flow is often stationary and the timescale of the spectral gap is roughly constant. However, in stably-stratified flows, the characterization of turbulent motions is much more complex: non-statiorarity is a common feature, the position of the gap is variable and sometimes it is difficult or even impossible to define a suitable averaging length, because turbulent and larger-scale motions completely overlap.

The multiresolution decomposition (MR) is a multivariate and multiscale statistical tool which has become popular during recent years in the study of turbulence. The application of this technique for the evaluation of turbulent fluxes, known as multiresolution flux decomposition (henceforth referred to as MRFD), can reduce the uncertainty caused by the contamination of turbulent fluxes by large-scale structures. For a detailed description of the application of MRFD to micrometeorological studies, the reader is referred to papers by Howell and Mahrt (1997), Vickers and Mahrt (2003) and Voronovich and Kiely (2007). In the following lines, only a brief conceptual description of the method is outlined.

The method is an iterative filtering process. At every step, a time series of $2^{n}$ points is recursively filtered by subtracting non-overlapping moving averages of decreasing length $\left(2^{n-1}, 2^{n-2}, \ldots 2\right)$. After each iteration, the time series retains only fluctuations up to the timescale corresponding to the length of the last filtered moving average. At each step, the variance of the partially filtered time series is calculated. The spectrum of the time series is built up from the differences between consecutive variances, which represent the contribution to the total variance from structures of different timescales. In the same way, when applied to two time series of different variables (i.e., vertical windspeed $w$ and temperature $T$ ), the covariance is calculated at each step, and resulting multiresolution coefficients (the differences between consecutive covariances) represent the contribution to the total flux from structures of different timescales. Figure 2 shows a typical MRFD heat cospectrum under stable stratification. When studying turbulent cospectra either from MRFD or from other spectral methods such as Fourier or wavelet transforms, several features of the turbulence can be easily inferred, especially under stationary conditions, namely:

1. A local extremum (a peak in the cospectra) of maximum downward or upward flux, produced at a certain timescale which characterizes the mean turbulent eddies.

2. A timescale or range of timescales (longer than that related to the mean turbulent eddies), where the contribution to the total flux is small or null. This is the gap separating turbulence from mesoscale motions. A vertical line on Figure 2 marks the timescale of the gap.

3. The distribution of the turbulent eddies along the different timescales or, alternatively, length scales (using Taylor's hypothesis of frozen turbulence to convert from time to space). 


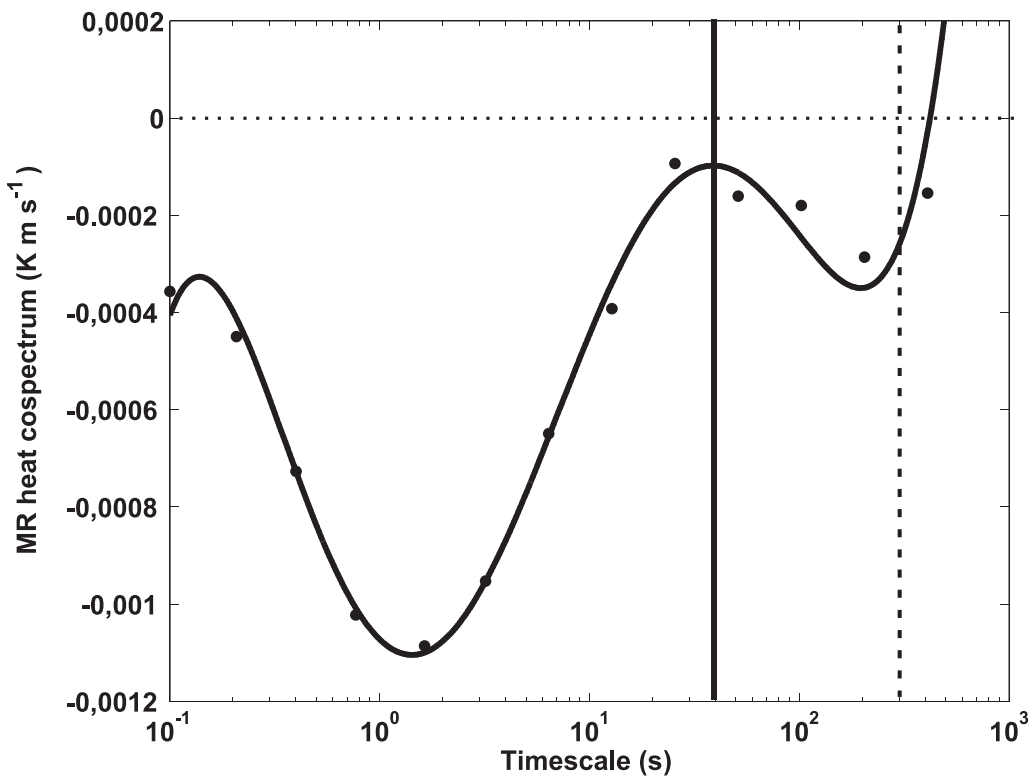

Fig. 2 Example of a typical MRFD heat cospectrum under stable stratification, showing the timescale characterizing the mean turbulent eddies (1-2 seconds), the location of the cospectral gap (30-40 seconds, vertical black line) and the typical 5-minute averaging length used in the eddy covariance method (dashed line).

Vertical heat flux cospectra for the whole night have been evaluated using 13.6-minute subseries ( 820 seconds, $2^{14}$ data points) of vertical velocity and potential temperature collected by the sonic anemometers set at $19.6 \mathrm{~m}$ and 96.6m AGL. Firstly, a planar-fit (long-term) rotation scheme (Nappo, 2002) was applied to raw sonic anemometer data to define the vertical axis $(z)$ and calculate the vertical wind component $(w)$. The timescale of the gap in the heat cospectra is determined individually for each heat cospectrum using an algorithm similar to that used by Voronovich and Kiely (2007): The coefficients of the cospectrum are fitted to a 5th-order polynomial, and then the gap is located according to a criterion based on the first occurrence of a zero crossing, an inflexion point or a minimum of the absolute value in the fitted 
cospectrum after the turbulent peak of maximum downward (negative) or upward (positive) heat flux.

\section{Results and discussion}

\subsection{Overview of the night}

In this section we briefly describe the synoptic situation prevailing on the Iberian Peninsula on July 11, and the nocturnal conditions established at CIBA during the night. Figure 3 shows the ECMWF 00 UTC analysis at the surface and at $500 \mathrm{hPa}$. The northern side of Spain is affected by high pressures due to the anticyclone located north of the Azores islands, while a low-pressure system is developing in the south-west (Fig. 3a). The 500$\mathrm{hPa}$ surface shows a very weak geopotential gradient over the peninsula (Fig. $3 b$ ), with a weak cyclonic circulation over the surface low-pressure system. According to Meteosat Second Generation (MSG) imagery, some convective cells close to the surface low were formed during the late evening and night (Fig. 3c), travelling northwards. Because of the absence of a strong dynamic forcing in mid-tropospheric levels, these cells were short-lived and provided small or null precipitation rates. Some small areas of showery rain around 300$500 \mathrm{~km}$ south of the experimental site were produced, but no thunderstorm activity was registered at the CIBA site. At the experimental site, skies were partially covered during the evening and early night hours, mainly by mid and high clouds with their base above $2500 \mathrm{~m}$. Fig. $3 \mathrm{~d}$ shows a sudden increase in the infrared channel in the region, approximately when the wave packet arrives at CIBA, suggesting the initiation of a convective cell.

The overall synoptic situation clearly explains why the night was probably one of the least stable ones of the whole campaign. During the daytime, the synoptic pressure gradient favours an easterly flow over the northern Spanish plateau. This pressure gradient is strong enough to maintain a near-neutral ABL during the night-time, as opposed to many nights from the SABLES2006 field campaign, where weaker winds and significant surface cooling favoured the development of a stably stratified boundary layer in the late evening and the establishment of a katabatic circulation from north-east, which modulates the stratification (Yagüe et al., 2007; Viana et al., 2008). Therefore, the transition from daytime convective conditions to the night-time regime during this night took place smoothly and did not produce abrupt changes, either in the flow circulation or in the stratification. Wind shear was intense over the first few metres (Fig. 4a), and no surface-based temperature inversion was formed; from 2000 UTC, close to neutrality conditions developed at tower levels instead (Fig. 4c). Consequently, gradient Richardson numbers took positive values close to zero (Fig. $4 \mathrm{~d}$ ).

The effects of the propagation of the mesoscalar gravity wave along the experimental site are noticeable in wind and temperature records as well as in stability parameters evaluated at any tower level from 0230 to 0430 UTC 


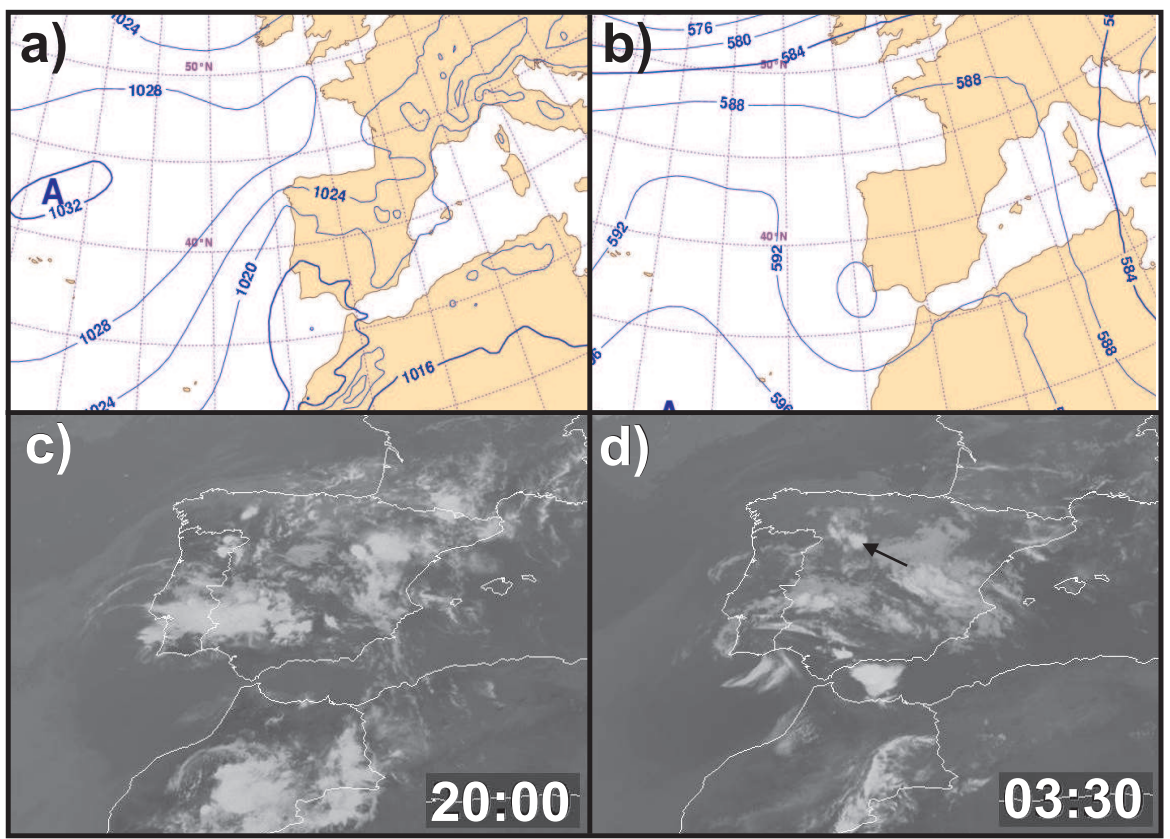

Fig. 3 Surface (a) and 500-hPa (b) analysis from the operative model ECMWF at 00 UTC, and synoptic IR imagery from MSG at 2000 UTC (c) and 0330 UTC (d). An arrow marks the approximate location of the CIBA site.

approximately (Fig. 4). Among these are, specifically, periodic oscillations in windspeed and wind direction, decrease of wind shear, development of a temperature inversion and consequent increase in the stability $\left(R i_{g}\right)$. These features will be discussed thoroughly in subsequent sections.

4.2 The parameters of the wave and its mesoscale extent

Figure 5 shows the absolute pressure record from one of the surface microbarometers, and the same record after removing the synoptic and "barometric tide" components by using a first-order Butterworth filter with a cut-off frequency of $\mathrm{f}=1 / 3600 \mathrm{~s}^{-1}$. A quite distinctive periodic fluctuation is clearly visible between 0230 and 0430 UTC approximately, superimposed on the negative synoptic pressure tendency prevailing for most of the night. The filtered time series (Fig. 5b) shows more clearly the shape of the wave and the temporal limits of the event. The maximum amplitude of the pressure fluctuations due to the wave is around $0.5 \mathrm{hPa}$, one order of magnitude larger than the typical pressure fluctuations related to waves in the SBL (Nappo, 2002; Viana et al., 2007). The smaller and fast pressure perturbations due to turbulence registered during the rest of the night are not present during the event. Einaudi 

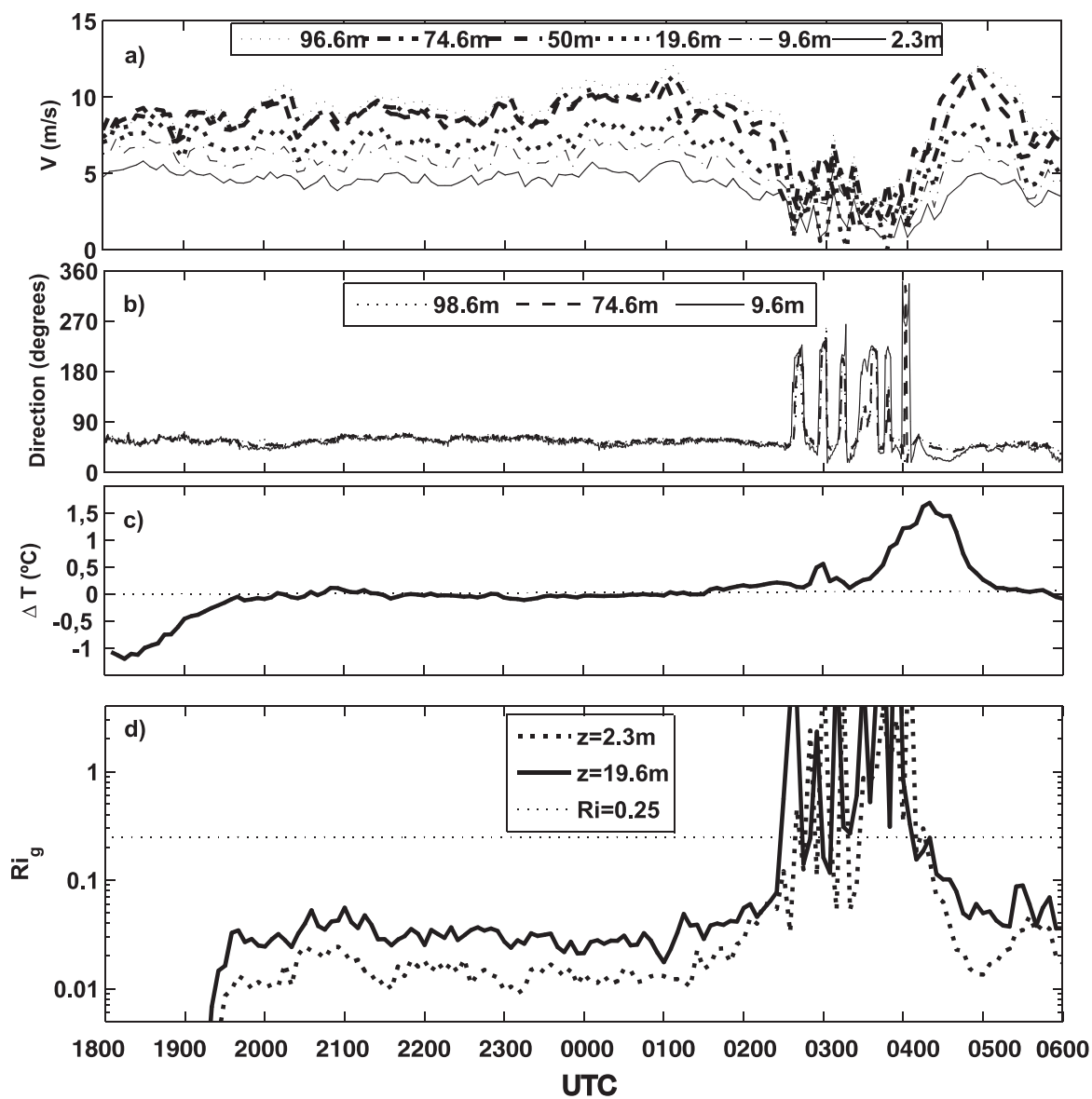

Fig. 4 Windspeed (a) and wind direction (b) at different tower levels, temperature difference between $35.5 \mathrm{~m}$ and $2.3 \mathrm{~m}$ (c) and gradient Richardson number evaluated at $19.6 \mathrm{~m}$ and $2.3 \mathrm{~m}$ (d) during the night of July 11.

\& Finnigan (1993) also reported smoother pressure signals in the presence of gravity waves as a result of the combined action of the greater amplitude of the wave pressure and a bias towards lower frequencies produced in the local surface pressure due to the contribution of velocity and temperature fluctuations over the entire air column (as described by the Poisson equation). The filtered pressure series from the microbarometers located on the surface array and at $20,50 \& 100 \mathrm{~m}$ look almost identical during the event (not shown): the sensors virtually register the same atmospheric phenomena: because of the integrative character of the atmospheric pressure, this suggests that the bulk of the atmospheric motions due to the wave was produced above $100 \mathrm{~m}$.

The parameters from the gravity wave were derived according to the methodology described in Section 3.1. After processing the wavelet transform from the 


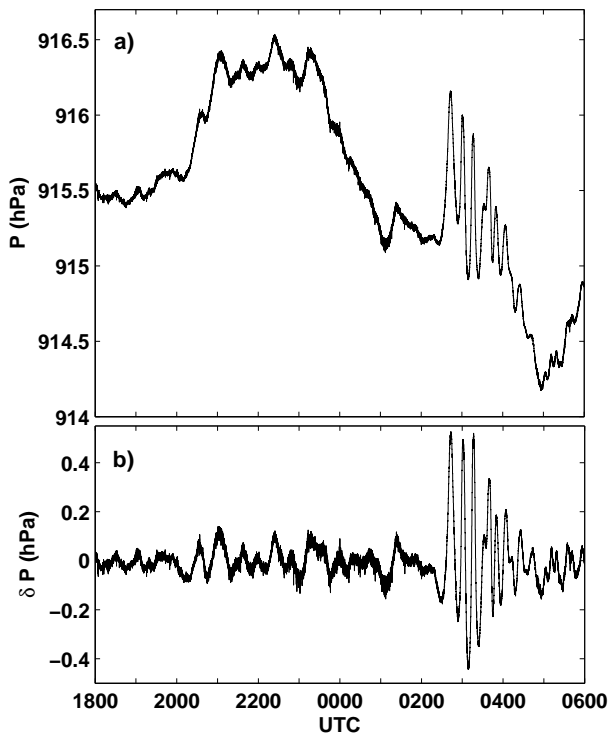

Fig. 5 Time series of absolute pressure (a) and filtered pressure (b) from a surface microbarometer during the night of the gravity wave event

surface pressure time series, a strong peak in the time-frequency space could easily be located with a period of around 16-17 minutes (Fig. 6a). In principle, the wavelet coefficients corresponding to the precise period and time from the wavelet maximum could be used to solve the system on Eq. 4 and evaluate the wave parameters (Eq. 5). However, it is advisable to select a region of the time-frequency space surrounding the maximum, and solve the system for each set of wavelet coefficients on this region. Results are presented using time-frequency maps of the wave parameters. A slow variation of these parameters close to the time and period where the maximum in the wavelet modulus is located gives confidence to the values found. On the contrary, when large gradients appear both in time and frequency direction, the structures on the different points of the array may be showing an independent evolution, and the spectral peak may be falsely significant (Terradellas et al., 2001). From the parameters of the wave shown in Figures 6b-d, it may be concluded that the coherent structure propagated towards north-east with a period of around 14-17 minutes, a phase speed in the range of $8.5-9 \mathrm{~m} \mathrm{~s}^{-1}$ and an estimated wavelength between 8 and $9 \mathrm{~km}$ approximately.

Before proceeding with the rest of the study based on local measurements, an attempt was made to estimate how large was the area affected by the wave propagation. We gathered pressure data from neighbouring stations belonging to the AEMET network (the Spanish Meteorological Service). These stations have a temporal resolution of 10 minutes, so we cannot expect to observe the 

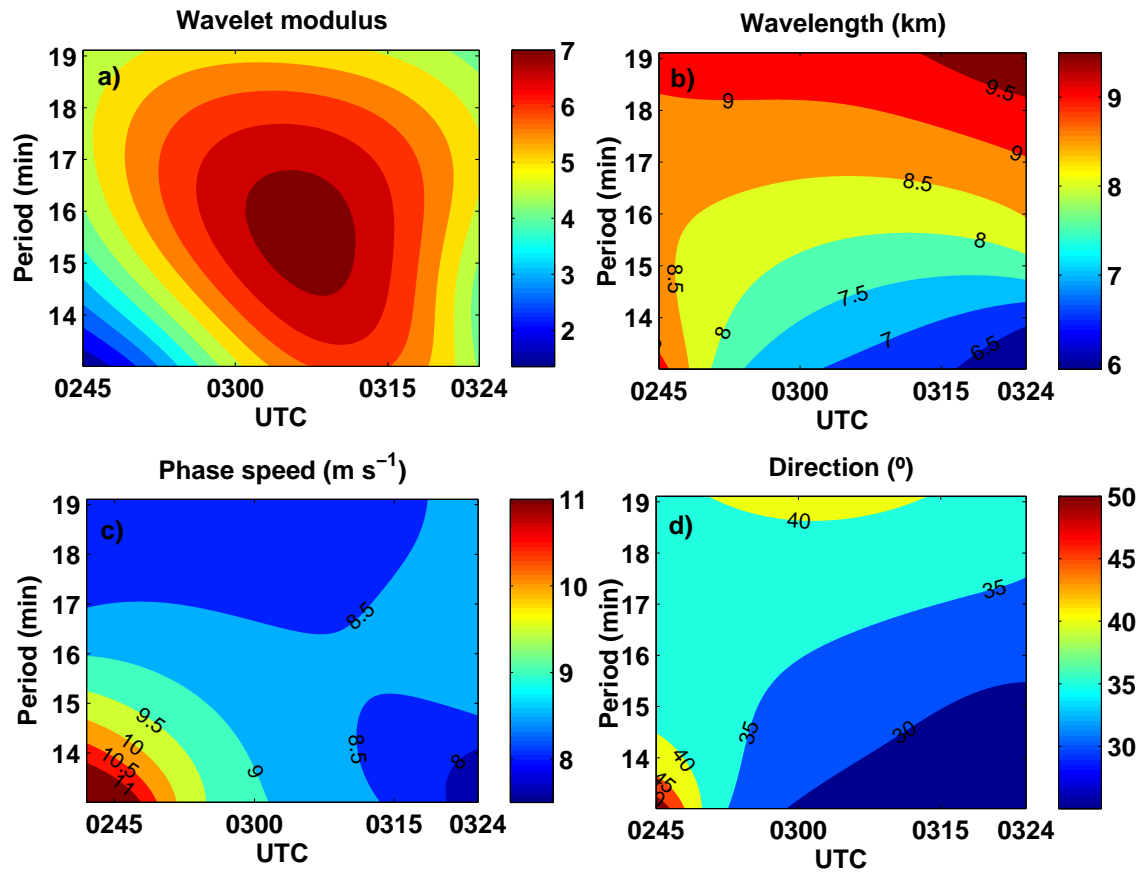

Fig. 6 Wavelet modulus (a), wavelength (b), phase speed (c) and direction of propagation (d) for the coherent structure detected on 12 July at 0215 UTC.

wave ridges and troughs. However, the pressure jump preceding the periodic oscillations (similar to that registered around 0230 UTC at CIBA, Figure 5 ), could be tracked along the different stations. Figure 7 shows the pressure records of four of the stations, which have been ordered according to the arrival time of the pressure jump (marked by an arrow on each plot). A careful analysis of the location of the stations (Fig. 1a) and the different arrival times of the perturbation to the different sites also suggests propagation towards northeast, along a distance of more than $200 \mathrm{~km}$. This can be checked with the help of the north-east-directed wave front depicted in Figure 1a. The perturbation spends nearly two hours in travelling from station 1 to station 4, separated by nearly $70 \mathrm{~km}$ along the south-west - north-east axis; the phase velocity deduced from these data is in good agreement with the more precise results from wavelet analysis. According to this, the wave presumably preserved its coherent character throughout most of its lifetime.

\subsection{Wave-induced local effects at CIBA}

In this section we describe in more detail the trace of the wave propagation on the different variables, and compare the observations with the predictions from 


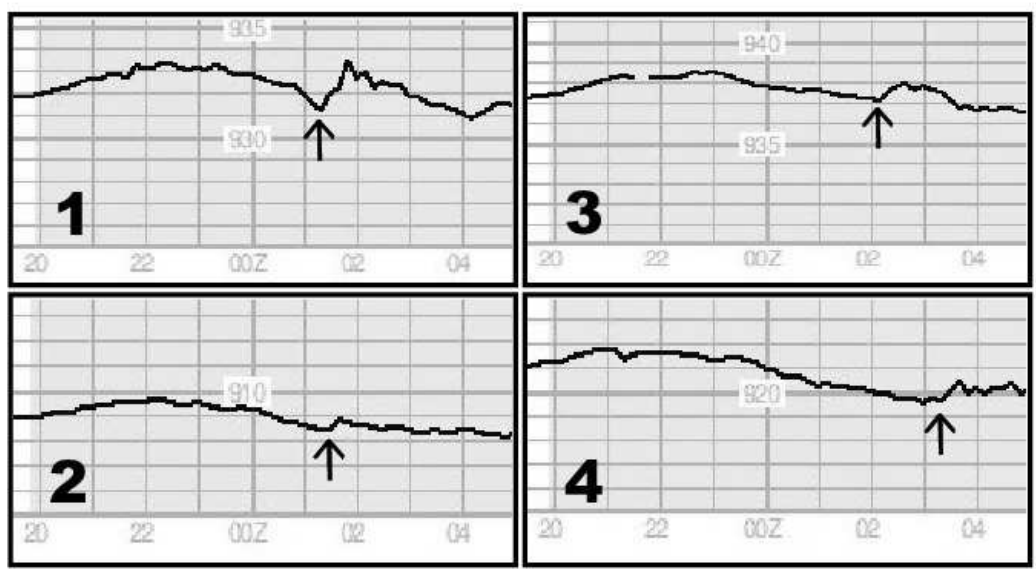

Fig. 7 Pressure series from neighbouring AEMET's automatic stations. Arrow marks the pressure jump at the arrival of the wave packet. See the precise location of these stations on Figure 1a.

the linear wave theory. In Figure 8, minutely-averaged values of windspeed and temperature during the wave event are shown, together with the filtered time series of the surface pressure. The north-east synoptic wind shifts to the opposite direction (south-west) every few minutes. Recall from previous sections that the phase velocity of the wave is also directed from south-west to north-east. Windspeed and pressure fluctuations are in phase, so that the flow is from north-east during wave troughs and from south-west during wave ridges. Short calm periods are produced as the flow from north-east veers to south-west and vice versa. According to Taylor-Goldstein's polarization equations from the linear wave theory, gravity waves propagating over a wavesupporting atmospheric layer produce fluctuations $(\delta U)$ in the component of the wind projected in the direction of the wave propagation (i.e., $\mathrm{U}=|\mathrm{V}| \cos (\alpha)$, where $\alpha$ is the angle between $\mathbf{V}$ and $\mathbf{k}$ ). These windspeed fluctuations and the surface pressure fluctuations $\delta p$ are related by the following expression (Nappo, 2002):

$$
\delta U=\frac{\delta p}{\rho_{0}(c-U)}
$$

where $\rho_{0}$ is the air density. Generally, the mean windspeed vector is not aligned with the wavenumber vector, so that the fluctuations forced by the wave produce only limited oscillations in the total mean windspeed, and wind direction veers around its mean value with an amplitude which is proportional to the misalignment between the wind and the direction of the wave. However, in this case study the mean synoptic flow and the wavenumber vector have nearly opposite directions, so that a direct confrontation between both is produced at the arrival of the wave packet at CIBA, (i.e., the windspeed 
fluctuations affect the whole windspeed vector, not just a component). This feature explains the strong coupling produced between the wave and the wind. During the event, the mean wind $U$ from the above equation is close to zero, due to the periodic veering in the wind direction. Taking this into account, using the phase velocity of the wave derived from wavelet analysis $\left(9 \mathrm{~m} \mathrm{~s}^{-1}\right)$ and the observed maximum amplitude of the pressure fluctuations (nearly 50 $\mathrm{Pa}$ as shown on Fig. 8c), equation 6 predicts fluctuations $\delta U$ of around 5 $\mathrm{m} \mathrm{s}^{-1}$, a good approximation to the actual amplitude of the fluctuations as shown in Fig. 8d, where the wind at $z=9.6 \mathrm{~m}$ and $z=96.6 \mathrm{~m}$ has been projected in the direction of the wavenumber vector resulting from the wavelet analysis in the previous section. Other quadrature relationships expected from the linear wave theory were not so closely achieved: Fig. 8e shows the presence of a phase lag between temperature and vertical velocity at $z=96.6 \mathrm{~m}$, also present between temperature and humidity (not shown). The expected $\pi / 2$ phase lag (in presence of waves) is not quite clear mainly because the noisy shape of the measured temperature and humidity fluctuations.

More features of the wave are observed at heights above the CIBA tower. Figures $9 \mathrm{a} \& \mathrm{~b}$ show the time - height profiles of temperature and windspeed projected in the direction of wave propagation, extracted from RASS-SODAR data. The south-west directed flow (wind from north-east) forms a low-level jet (LLJ) with a wind maximum around 220-250 metres (negative values in Figure $9 \mathrm{~b}$ due to the coordinate system). The level of this LLJ is much higher than those typically appearing in the SBL at CIBA (Conangla and Cuxart, 2006; Conangla et al., 2008). The amplitude of the periodic temperature fluctuations increases with height, with a maximum of about $4-5^{\circ} \mathrm{C}$ between $300-$ $350 \mathrm{~m}$. In contrast, windspeed fluctuations are produced with similar amplitude along the whole atmospheric layer explored by the RASS-SODAR. As a result, the intervals of reversed (south-west) flow direction are shorter as they come closer to the nose of the LLJ, a feature which is also noticeable on Figs. 8b \& 8c. Unfortunately, vertical velocity is not included in RASS-SODAR data; therefore no information can be inferred about the strength of the vertical motions or the fulfilment of the $w$-T phase relationship at levels above $100 \mathrm{~m}$.

\subsection{The wave duct}

Mesoscale gravity waves produce high-amplitude vertical motions over deep and extensive atmospheric layers. Regardless of the specific process responsible for the initiation of the gravity wave, some additional mechanism is needed in order to keep the wave active. Otherwise, the energy of these waves would dissipate through vertical propagation soon after their formation (Lindzen and Tung, 1976; Uccellini and Koch, 1987). In certain mesoscale gravity waves triggered by strong, long-lived convective activity, large amounts of latent heat released in cumulonimbus provide a continuous energy source which can keep the waves active for hours. These waves in turn can modulate the convective activity, and organize cumulonimbus in regularly-spaced structures. Waves of 

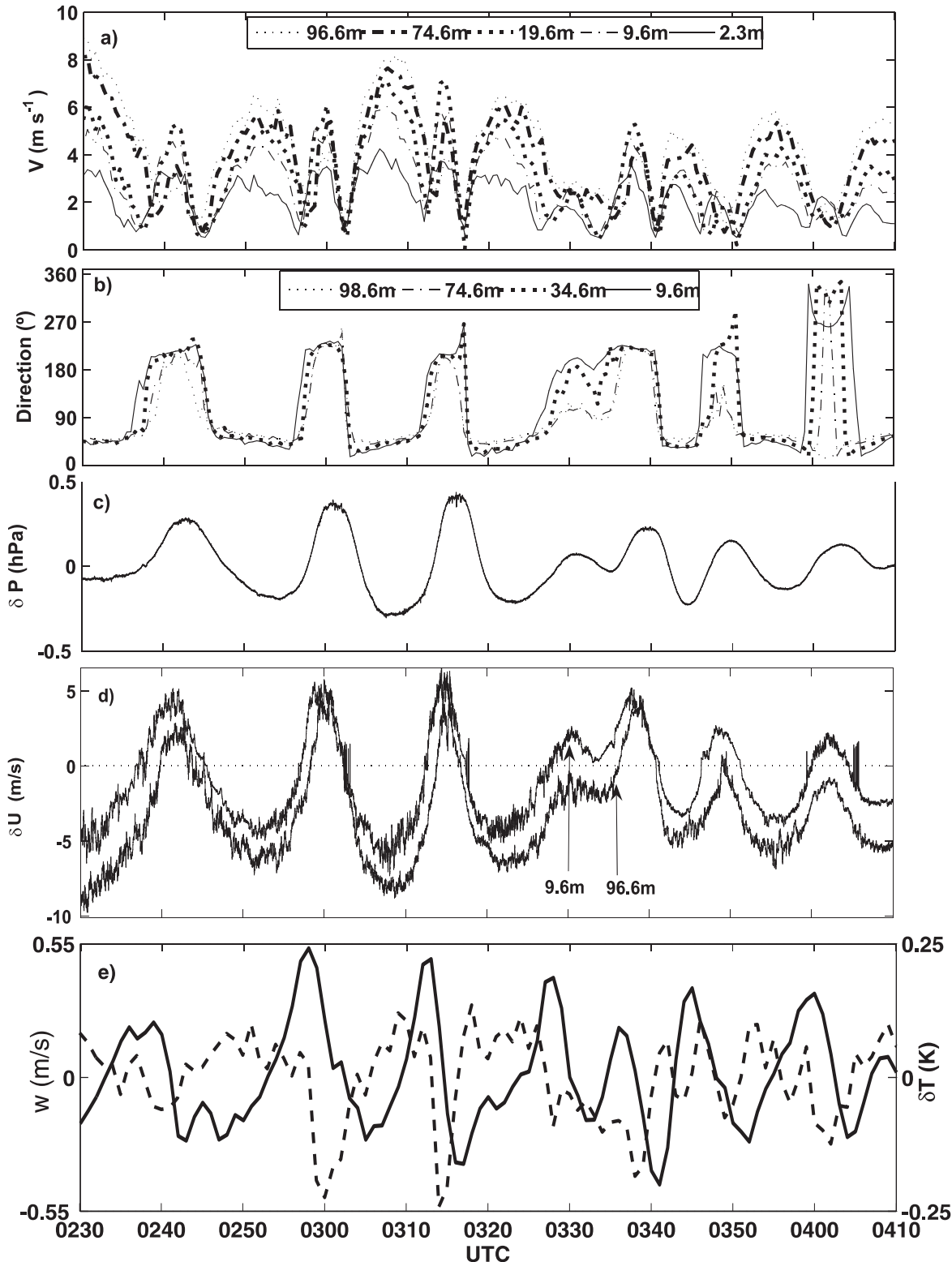

Fig. 8 Minutely averaged windspeed (a) and wind direction (b) at different tower levels, surface pressure fluctuations (c), windspeed projected in the direction of wave propagation at $z=9.6$ and $96.6 \mathrm{~m}(\mathrm{~d})$ and vertical windspeed (solid line) and temperature fluctuations (dashed line) at $z=96.6 \mathrm{~m}(\mathrm{e})$. 


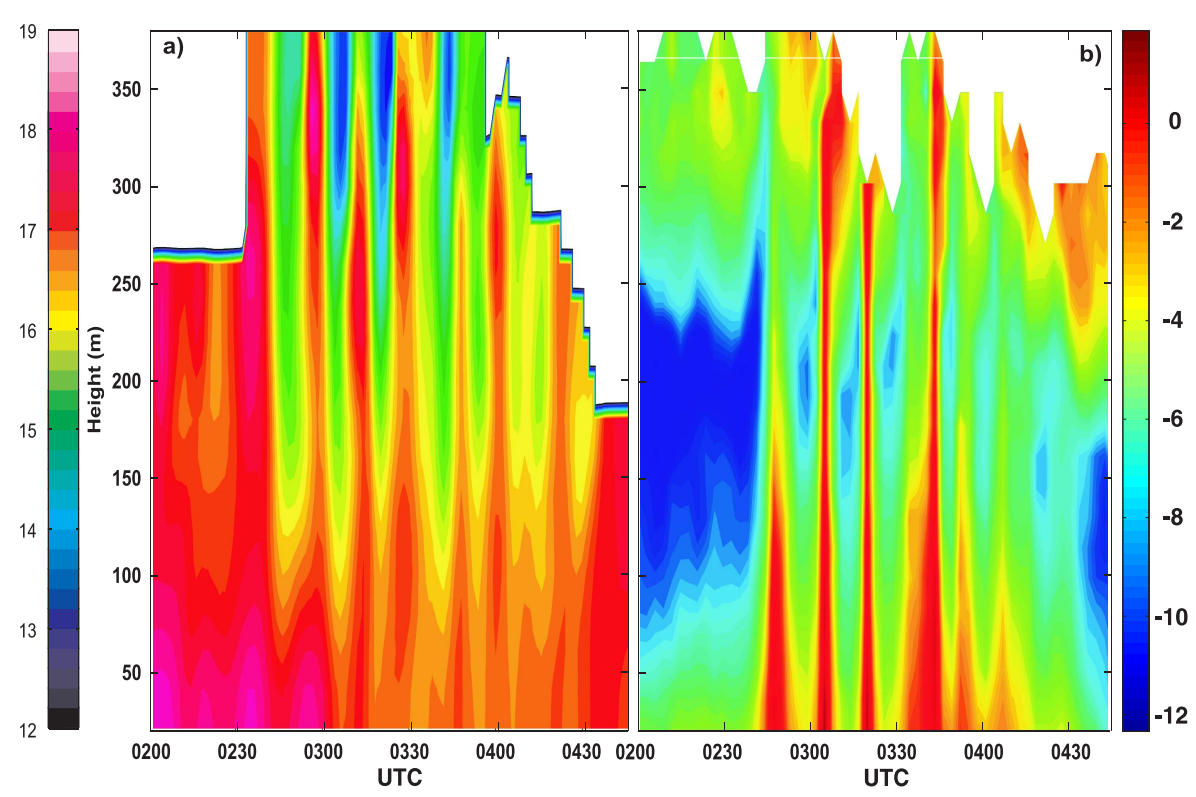

Fig. 9 RASS-SODAR time-height display of (a) temperature (in Celsius) and (b) windspeed (in $\mathrm{m} \mathrm{s}^{-1}$ ) projected in the direction of the phase velocity. Negative values are winds from north-east while positive values are from south-west.

this kind have typical wavelengths of $\mathrm{O}\left(10^{2} \mathrm{~km}\right)$ and phase speed of $\mathrm{O}(10$ $\mathrm{m} \mathrm{s}^{-1}$ ); such interactions are generally known as wave-CISK, or Convective Instability of the Second Kind (Lindzen and Tung, 1976). In contrast, in gravity waves generated by non-convective processes, or when convection is weak and shallow, some wave reflecting layer is needed for the horizontal propagation of gravity waves without large energy loss. This mechanism, known as wave ducting, has been studied analytically, for instance, by Jones (1968a,b), Lindzen and Tung (1976), Chimonas and Hines (1986), Uccellini and Koch (1987) and Wang and Lin (1999), and reported in field observations in several other papers (Ralph et al., 1993; Fritts et al., 2003; Böhme et al., 2004, etc). The basic properties of a wave duct are derived straightforwardly from the Taylor-Goldstein equation (Gossard and Hooke, 1975):

$$
\frac{d^{2} w^{\prime}}{d z^{2}}+m^{2} w^{\prime}=0
$$

Here $m$ is the vertical wavenumber, defined as:

$$
m^{2}=\frac{N^{2}}{c_{i}^{2}}+\frac{\bar{U}_{z z}}{c_{i}}-k_{h}^{2}-\frac{1}{4 H^{2}}
$$

where $N^{2}=(g / \theta) \frac{\partial \theta}{\partial z}$ is the square of the Brunt-Väisälä frequency, $c_{i}=c-U$ represents the intrinsic phase velocity (relative to the mean flow), $U_{z z}$ is the second derivative with height of the mean wind in the direction of propagation, 
and $H$ is a height scale of the atmosphere. The vertical wavenumber is real in regions where wave propagation is possible, and complex in regions where waves are evanescent. Therefore, the first and most important property of a wave duct is to show positive values of $m^{2}$ over a sufficiently deep atmospheric layer. By using wind and temperature profiles derived from RASS-SODAR data and the wave parameters $\left(c, \mathbf{k}_{h}\right)$ derived in Section 4.2, the vertical profile of $m^{2}$ can be inferred. When doing this, the question arises of precisely which mean profiles of windspeed and temperature to use. The mean of the records during the wave event is not representative of the 'undisturbed' state that constitutes the background flow where the wave propagates; therefore we used the mean windspeed and temperature profiles from 0100 to 0200 UTC, prior to the wave arrival. The counterpart is that the temperature profile at this time is available only up to around $300 \mathrm{~m}$ due to the SODAR's inability to measure reliable temperature data above the low level jet. However, a close inspection of the relative contribution of the different terms in $m^{2}$ revealed that the majority of the contribution to $m^{2}$ is due to the curvature of the wind profile (second term in Eq. 8): since the wave moves against the synoptic wind, the squared intrinsic phase velocity $c_{i}$ is very large, and the first term in Eq. 8 is small irrespective of the strength of the static stability $(N)$. Therefore, we consider irrelevant the errors produced by the extrapolation of the fitted temperature profiles up to heights above $300 \mathrm{~m}$.

Results for the vertical profile of $m^{2}$ are shown in Figure 10. Local maxima of $m^{2}$ are found around 80 and 250 metres. The latter value coincides with the local windspeed maximum (actually a minimum in the coordinate system) of the south-west-directed LLJ. The vertical wavenumber is positive from 60 to $325 \mathrm{~m}$. The profile was expected to remain positive at least up to $350-380 \mathrm{~m}$, where temperature fluctuations revealed from SODAR data are still intense; a possible explanation could be related to a poor representation of actual wind conditions by the SODAR above the LLJ, given the high sensitivity of the results to the curvature of the wind profile.

The picture emerging here is that of a wave propagating along a LLJ blowing in the opposite direction. This is a singular case compared to most examples of mesoscale gravity waves in the literature, which propagate in the same direction as the mean flow (or, at least, with an important component of the phase velocity aligned with the mean flow). Chimonas and Hines (1986) performed an analytical study of waves ducted horizontally in a stably stratified atmosphere with levels of maximum or minimum wind, a process known as Doppler ducting. They argued that the mechanism should be available to a part of the spectrum of gravity waves admitted by a given atmospheric state. The specific case of a gravity wave propagating against a LLJ flowing in the opposite direction was not analysed - but, as they pointed out, a simple transformation of the observing coordinate system can change a wind maximum into a wind minimum (or equally, a wind minimum into another wind maximum in the direction of negative windspeeds), without affecting the physical process. A rigorous analytical derivation of the spectrum of gravity waves available to the atmospheric conditions existing in our case is beyond the scope of this pa- 


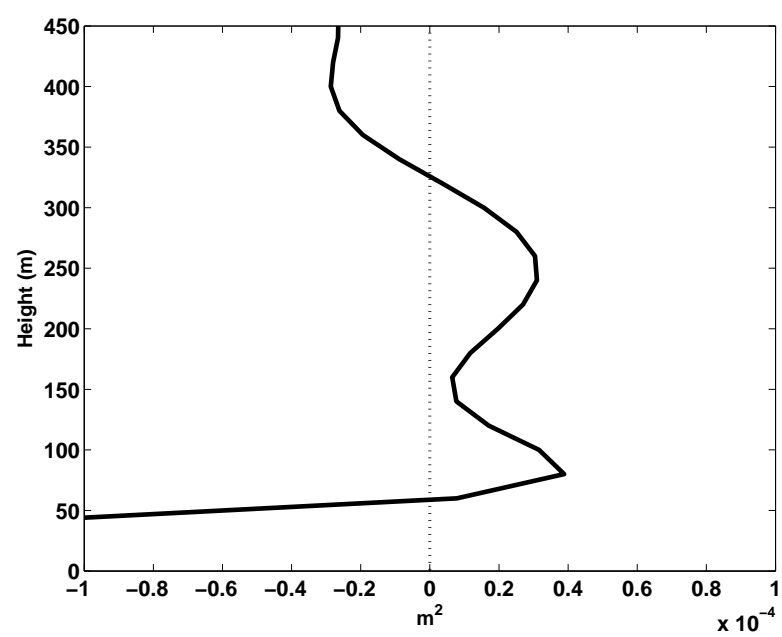

Fig. 10 Profile of the squared vertical wavenumber.

per. However, we judge the proposed mechanism more suitable to the present case than others based on a mixture of dynamic and thermal requirements, such as a prescribed minimum thickness of the wave duct, the existence of a conditionally unstable layer capping the duct, interactions with critical levels, concurrence of certain synoptic patterns at surface and upper atmospheric levels, etc (Eom, 1975; Lindzen and Tung, 1976; Uccellini and Koch, 1987; Koch et al., 1993; Koch and O'Handley, 1997; Koch and Saleeby, 2001).

\subsection{Wave-turbulence interaction}

Virtually all observations of gravity waves developed in stably stratified atmospheric boundary layers occur in conjunction with a certain amount of turbulent activity. In the absence of wave activity the intensity, vertical extension and time span of turbulent motions are mainly controlled by the background atmospheric conditions. However, high values of the mean Richardson number in the presence of gravity waves do not support a steady, homogeneous generation of turbulence; the unsteadiness in the flow and the modified instantaneous fields of windspeed and temperature caused by the wave are then the main cause for turbulence generation. The dynamics of the interaction between gravity waves and turbulence has been studied in a number of experimental and theoretical studies during the last few decades. Einaudi and Finnigan (1981;1993), Finnigan and Einaudi (1981), Finnigan et al. (1984) and Finnigan (1988) studied these interactions from field data through an explicit separation of every flow variable into mean, wave, and turbulence fields (i.e.: $a=\bar{a}+\tilde{a}+a^{\prime}$ ). However, the conditions needed to apply this triple 
decomposition (i.e., to observe a nearly monochromatic wave for a significant period of time, typically 8-10 wave cycles) are rarely met in most gravity waves observed in the atmosphere. Furthermore, as noted by Chimonas (1999), computed 'wave-mean' fluxes (i.e., heat or momentum transfers produced by motions at the scale of the wave) may become contaminated by spurious nonwave-related contributions, such as temperature steps swept up and down the measurement level by the wave.

In this section, we use the results from MRFD to explore the impact of the propagation of the wave on the structure of the turbulence. Multiresolution analysis allows us to observe simultaneously the different timescales contributing to vertical transports, and the temporal evolution of these transports during the night. Figure 11 shows with contour plots how the contribution of different timescales to the heat cospectra changes during the night. Every vertical slice in the figure may be thought of as a different MR cospectrum (as in Fig. 2), with blue colours for negative (co-gradient) contributions and red for positive (counter-gradient) contributions. In this and subsequent plots, different subseries used to evaluate spectra and cospectra overlap every 60 seconds, in order to provide a good temporal resolution in the time axis.

The nocturnal undisturbed turbulent regime shows approximately stationary conditions until 0230 UTC. The strong wind shear below the LLJ and the small but negative buoyancy force due to the near-neutral conditions existing close to the surface provide the perfect environment for the establishment of a small, continuous downward turbulent heat flux, with mean eddies characterized by timescales around $10 \mathrm{~s}$ (the average position of the turbulent maxima in cospectra). The mean position of the spectral gap is around $200 \mathrm{~s}$, and the average turbulent eddies have an associated timescale around $10 \mathrm{~s}$. This turbulent regime is recovered after 0430 UTC, when the wave packet has left the site.

The features described as well as others shown in subsequent figures ( $T K E$, $u_{*}$ ) fit reasonably well with present knowledge on weakly stratified boundary layers, both through observation and LES studies (Jiménez and Cuxart, 2005; Beare et al., 2006; Cuxart and Jiménez, 2007). Some particularities typical of weakly-stratified and strong-wind regimes refering to the organization of the bigger eddies (of up to $100 \mathrm{~m}$ length) into large 'streets' elongated in the direction of the mean wind (see Andrén et al., 1994; Drobinski and Foster, 2003 and references therein) cannot be easily verified from one-point measurements.

The effects produced by the propagation of the mesoscale wave along the site are clearly visible starting at 0230 UTC. Vertical heat transfer at $z=19.6 \mathrm{~m}$ by turbulent timescales $(<100 \mathrm{~s})$ is reduced or cancels, i.e., turbulent motions decay. This is not unexpected since the stability close to the surface increased during the event (Fig. 4c). It is not clear however why the smaller turbulent timescales $(<10 \mathrm{~s})$ seem to be more affected than timescales from 10 to 100 seconds, which at times remain unaffected (e.g., at 0300 and 0345 UTC), showing values similar to the previous hours. As a consequence of this, the timescale of the maximum downward turbulent heat flux (red line), which characterizes the mean transporting eddies, is greater than in the previous 


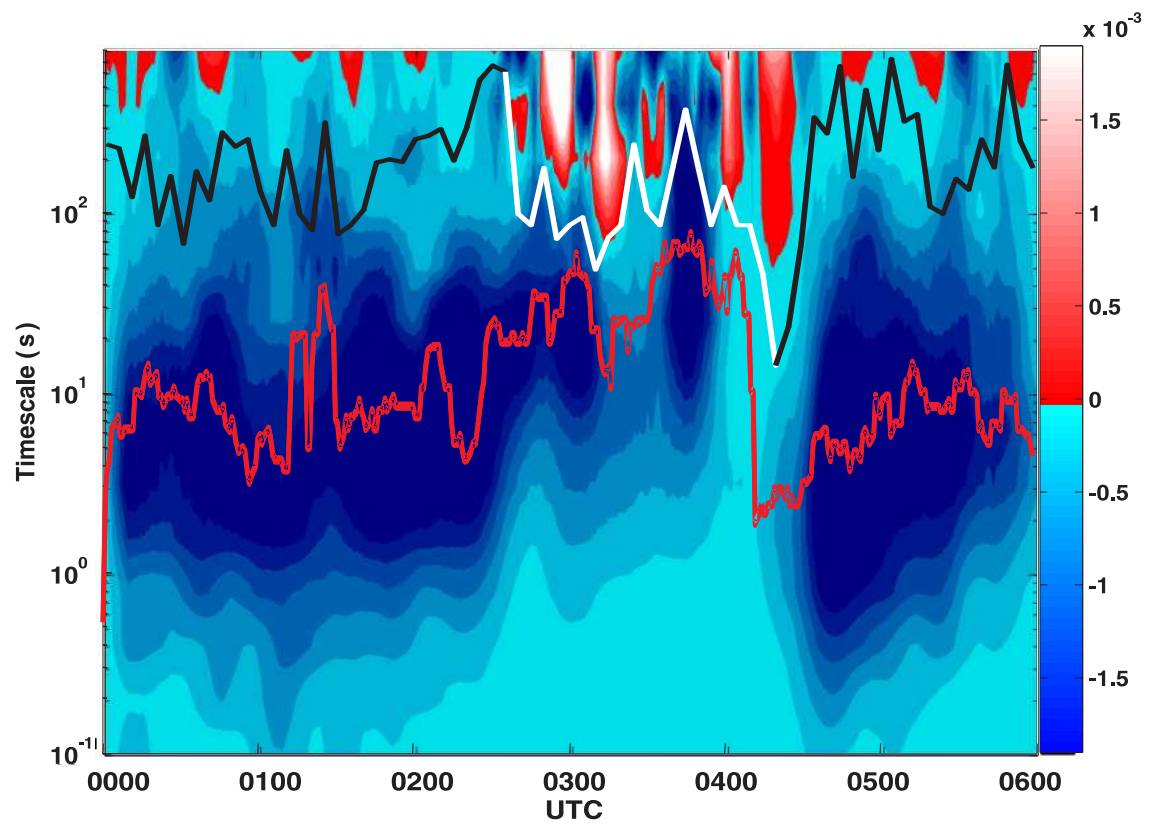

Fig. 11 Multiresolution flux decomposition of the heat flux (in $\mathrm{K} \mathrm{m} \mathrm{s}^{-1}$ ) at $z=19.6 \mathrm{~m}$. Black-white and red lines mark the timescale of the spectral gap and of the mean turbulent eddies, respectively.

hours during most part of this period. A possible explanation is the following: during the wave event, the higher stability makes these eddies smaller, but they move slower because the windspeed has decreased compared to earlier values. If the decrease in the length scale is weaker than that corresponding to windspeed, using Taylor's hypothesis $(\tau=\ell / \mathrm{V})$ an increase in the mean eddy timescale is expected. Mahrt and Vickers (2006) found a similar behaviour when comparing composite multiresolution heat flux cospectra for strong and weak turbulent regimes.

Prior to 0230 UTC and after 0430 UTC, the heat flux due to timescales greater than the spectral gap is small. Since the wave is not active during these periods, the negligible vertical exchange of heat produced in these timescales is a spurious contribution due to mesoscale motions. In principle these may be of either sign irrespective of the local gradients. In the present case, except for some positive counter-gradient values at the largest timescales, the total heat exchange provided by these timescales is slightly negative and is probably biased by the largest turbulent eddies with timescales of the order of the spectral gap. In contrast, during the wave event, wave-related motions have a remarkable contribution at timescales larger than the turbulent peak in the cospectra. Turbulence and wave cospectra overlap along timescales close to $100 \mathrm{~s}$, which is the reason why the estimate of the spectral gap during that 
period (white line) is not very reliable. This wave-related heat flux changes from positive to negative values every few minutes in an irregular way. This section of the time-cospectrum plot could be interpreted as the instantaneous value of the 'wave' heat flux $(\overline{\tilde{w} \tilde{\theta}})$ from the triple-decomposition method. Of course, it is not really instantaneous, because each MR cospectrum is built with time subseries of $820 \mathrm{~s}$ length, but since the different subseries overlap so that there is one cospectrum per minute, it is a good approximation. Finnigan et al. (1984) and Einaudi and Finnigan (1993) also found counter-gradient values of $\overline{\tilde{w} \tilde{\theta}}$ in their analysis of different gravity waves events measured at the Boulder Atmospheric Observatory.

Turbulent heat flux is much weaker during most of the night at $z=96.6 \mathrm{~m}$, as is deduced from the heat flux cospectra shown in Fig. 12. The temperature profile is much more homogeneous at this level than closer to the surface, and so is the wind shear. Consequently, the majority of the individual MR heat cospectra composing this figure have a roughly flat shape. When the turbulent heat flux is so weak, the precision of the sonic anemometers is of great importance in order to resolve correctly the spectrum of the turbulent motions. In addition, the relative error is greater for low vertical velocity conditions. As a result, the actual shape of the turbulent cospectra is poorly resolved, the peak in the cospectrum cannot be identified, and the algorithm fails to provide a realistic location for the spectral gap. Therefore, no spectral gap estimations are shown in this plot.

During the wave event, the wave-related heat flux is the most relevant contribution at $z=96.6 \mathrm{~m}$. It also takes positive or negative values, but at this level the strength of these fluctuating fluxes is significantly higher than at $z=19.6 \mathrm{~m}$. It corresponds to the flux produced by the phase lagged temperature and vertical windspeed time series from Fig. 8e. The expected period of the flux produced by two sinuisoidal signals (temperature and vertical speed) of period $\mathrm{P}$ with a phase lag of $\pi / 2$ is $P / 2$. Interestingly, although the phase lag between $w$ and $T$ is not stationary as shown in Fig. 8e, the wave heat flux in Fig. 12 apparently changes sign with a periodicity of nearly half the wave period. At higher levels above the ground, where periodic temperature fluctuations (and presumably, vertical windspeed fluctuations) are much stronger (Fig. $9 \mathrm{~b}$ ), this periodic component of the flux could be much more intense and homogeneous than at $z=96.6 \mathrm{~m}$, where both signals are weak. For a purely monochromatic and homogeneous wave, the total wave heat flux would be zero as prescribed by the linear wave theory. However, the wave studied here, as most gravity waves encountered in the atmosphere, away from laboratorycontrolled conditions, is not completely monochromatic (the periodicity in the pressure record changes after 0320 UTC, Fig. 8c), neither produces completely lineal interactions (otherwise variables such as $w, q$ or $T$ would be purely sinusoidal). Therefore, the total wave-heat flux could be different from zero.

Figures $13 \& 14$ depict the MR spectra for friction velocity $\left(u_{*}\right)$ and kinetic energy ( $K E$ ) during the night at $z=19.6 \mathrm{~m}$. When using Reynolds' decomposition and the eddy covariance method, these parameters are defined as follows: 


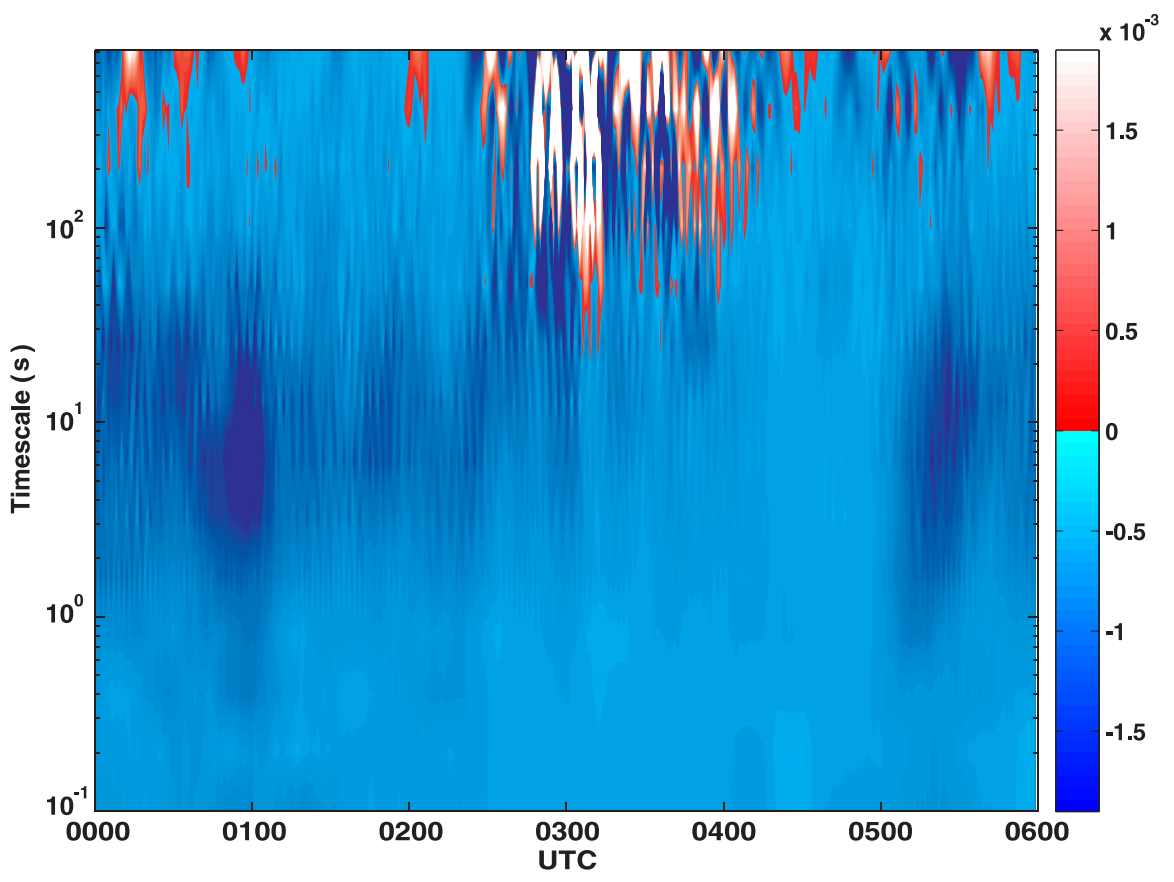

Fig. 12 Multiresolution flux decomposition of the heat flux (in $\mathrm{K} \mathrm{m} \mathrm{s}^{-1}$ ) at $z=96.6 \mathrm{~m}$.

$$
\begin{gathered}
u_{*}=\left[\left(-\overline{u^{\prime} w^{\prime}}\right)^{2}+\left(-\overline{v^{\prime} w^{\prime}}\right)^{2}\right]^{1 / 4} \\
T K E=\frac{1}{2}\left[\left(\overline{u^{\prime}}\right)^{2}+\left(\overline{v^{\prime}}\right)^{2}+\left(\overline{w^{\prime}}\right)^{2}\right]
\end{gathered}
$$

where $u$ and $v$ are the horizontal components of the wind, and primes denote, as usual, fluctuations about a mean state. In the context of MR decomposition, the contribution of every range of timescales can be calculated. Primes are substituted by a subscript corresponding to the timescale $\tau$ of the fluctuations :

$$
\begin{gathered}
u_{* \tau}=\left[(-u w)_{\tau}^{2}+(-v w)_{\tau}^{2}\right]^{1 / 4} \\
K E_{\tau}=\frac{1}{2}\left[\left(u^{2}\right)_{\tau}+\left(v^{2}\right)_{\tau}+\left(w^{2}\right)_{\tau}\right]
\end{gathered}
$$

Terms inside brackets in Eqs. 11-12 correspond, respectively, to the MRFD of along-wind and cross-wind momentum fluxes (cospectra), as well as the MRFD of the windspeed components (spectra), evaluated as described on 


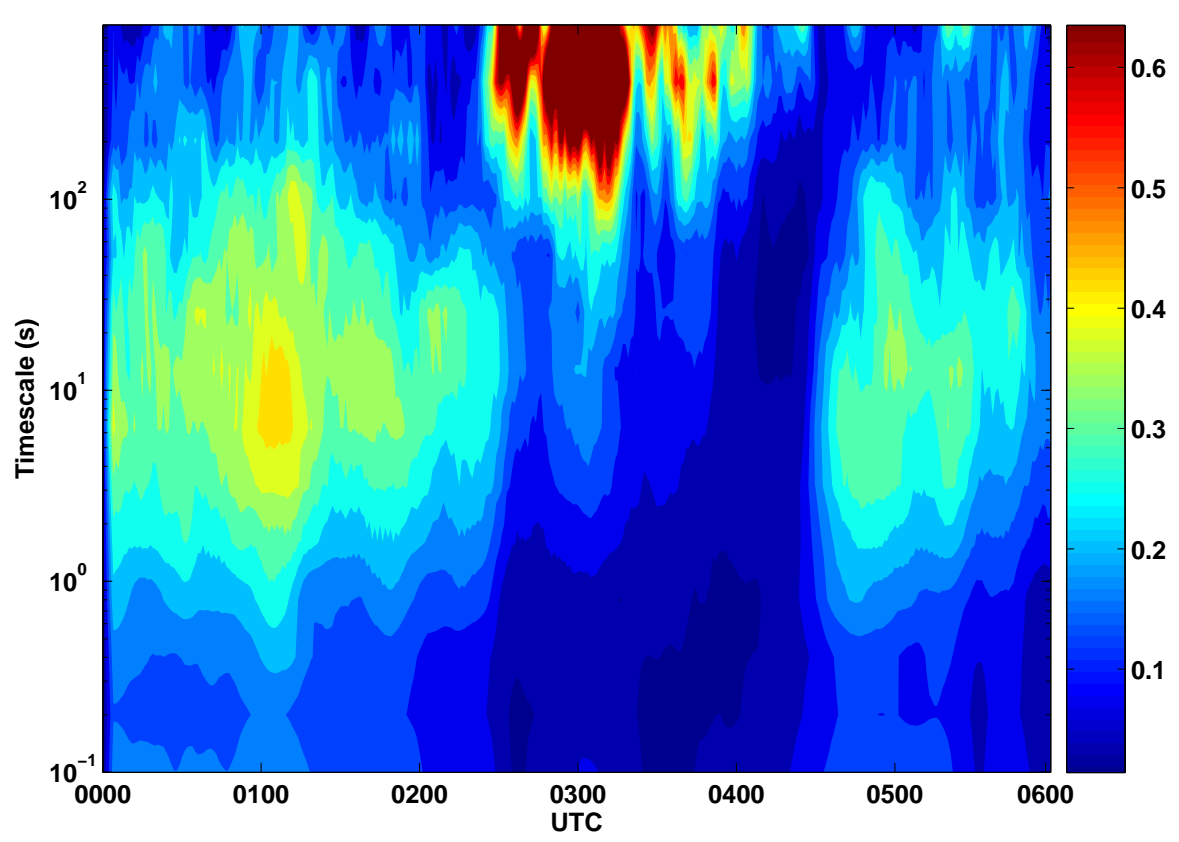

Fig. 13 Multiresolution decomposition of the friction velocity at $z=19.6 \mathrm{~m}\left(\mathrm{~m} \mathrm{~s}^{-1}\right)$. Darker red colours represent contributions around $0.4-0.6 \mathrm{~m} \mathrm{~s}^{-1}$

Section 3.2. Results shown in these plots for non-wave-related scales and time intervals are consistent with the turbulent regime (gap location, mean eddy size...) described in Fig. 11, although in these analysis the momentum flux is more intense than the corresponding heat flux. The total friction velocity and turbulent kinetic energy (i.e., their spectral components in Eqs. 11-12 integrated up to the spectral gap) during these periods have high values (not shown) compared to other nights of the campaign when the stability was of the same order but the wind regime was dominated by mesoscale circulations (i.e., katabatic and other topographically-induced winds) at the scale of the Duero basin (Viana et al., 2008).

During the wave event and for typically turbulent timescales $(<100 \mathrm{~s})$, the turbulent regime described by the MR decomposition of the friction velocity shows some differences with the heat flux. The decrease in wind shear reduces friction velocity more effectively than the turbulent heat flux: there is also some overlapping between turbulence and wave contributions, but one could intuitively define the boundaries between both of them more easily than using the heat flux decomposition. On the other hand, wave-related motions produce strong contributions to the friction velocity spectra, especially from 0230 to $0330 \mathrm{UTC}$, when timescales around $200 \mathrm{~s}$ and above show very large contributions, larger than the top value of the colour bar used in the contour plot. It is important to underline that during the event, these large contributions appear 


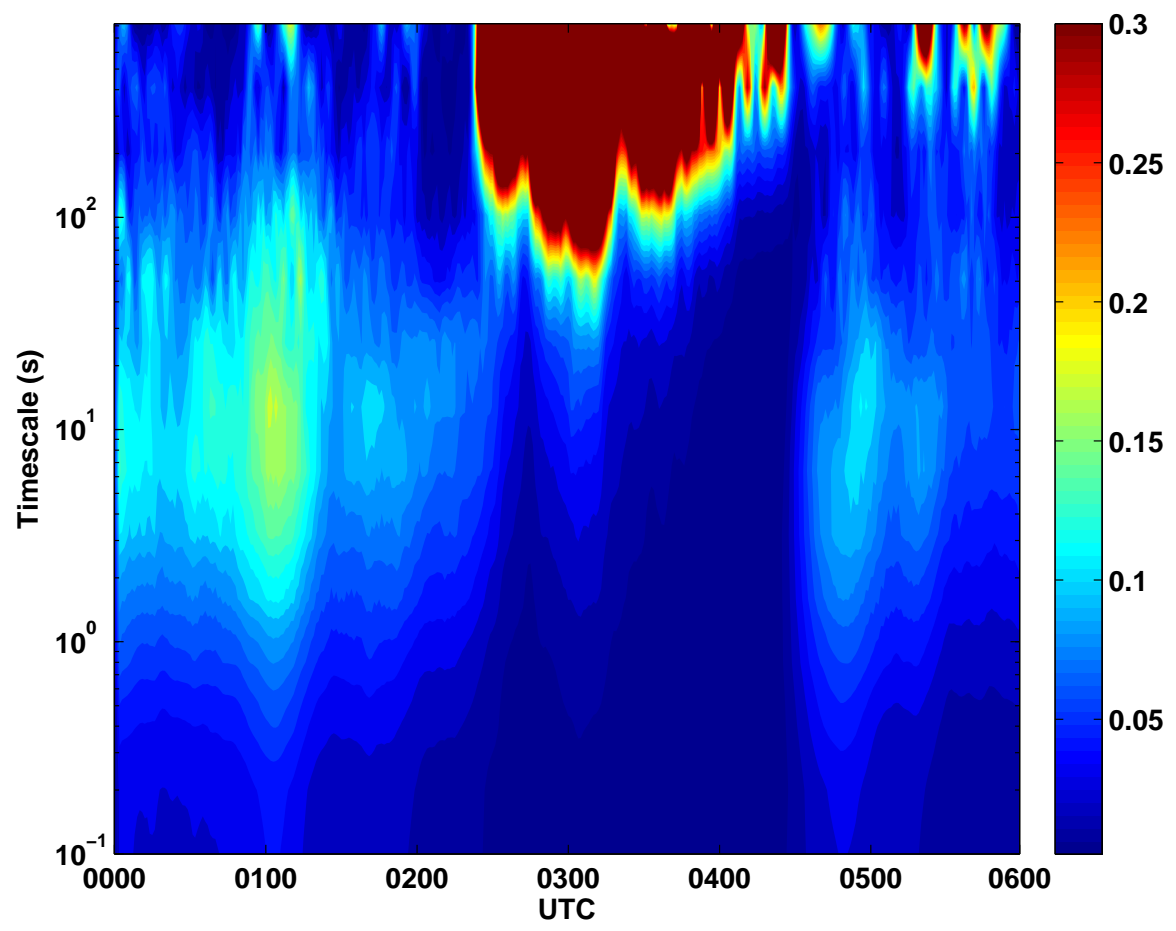

Fig. 14 Multiresolution decomposition of the kinetic energy at $z=19.6 \mathrm{~m}\left(\mathrm{~m}^{2} \mathrm{~s}^{-2}\right)$. Darker red colours represent contributions around $2-5 \mathrm{~m}^{2} \mathrm{~s}^{-2}$

due to the large fluctuations (of around $10 \mathrm{~m} \mathrm{~s}^{-1}$ amplitude and 16-17 min. period) produced in the horizontal along-wind component $u$; thus these values do not really have much to do with the existing wind shear. As expected, the strong wind fluctuations also induce large contributions to the kinetic energy, mainly at scales larger than $100 \mathrm{~s}$ and centred on larger scales (500s), falling outside the range of values used in the colour bar (around 2-5 $\mathrm{m}^{2} \mathrm{~s}^{-2}$ ). This highlights the importance of a proper filtering of non-turbulent-related contributions when estimating turbulent parameters such as TKE or $u_{*}$ in the presence of waves. A perfect filtering is hardly achieved and some turbulent signal may be lost in the process if both turbulence and waves overlap in a range of timescales. However, since the contribution of the wave is usually at least one order of magnitude higher than that of the turbulence, the filtering becomes critical to avoid extremely large values and unrealistic bursts leading to misinterpretations of the turbulent regime. 


\section{Summary and conclusions}

In this work, a complete micrometeorological study of an intense mesoscale gravity wave event profoundly affecting the structure of the ABL has been presented. The event, detected during the SABLES2006 field campaign, was produced during the night in a synoptic environment driven by easterly surface winds on the northern side of the Iberian Peninsula (wind from north-east at CIBA site) and a meso-low at upper levels of the atmosphere in the southern part of Spain, all in all an unfavourable pattern for the development of nocturnal stability. The nocturnal inversion was weak and the ABL was nearneutrally stratified at the experimental site. The stratification changed during the wave event and a moderate intermittent stability with $R i_{g} \geq 0.25$ was present.

We began with the study of the mesoscale characteristics of the wave and then our approach progressively zoomed to smaller scales until reaching micrometeorological properties. The wave was found to propagate from southwest to north-east along a distance of $\mathrm{O}(100 \mathrm{~km})$, with a lifetime of at least 2 hours. The maximum amplitude of the detected pressure fluctuations was 0.5 $\mathrm{hPa}$, one order of magnitude larger than the typical pressure waves detected in the ABL. From wavelet analysis, the main parameters of the wave were derived: period around 16 minutes, phase speed $9 \mathrm{~m} \mathrm{~s}^{-1}$ and wavelength $9 \mathrm{~km}$. Periodic temperature fluctuations were found to increase in amplitude with height, up to $4-5 \mathrm{~K}$ at $300-350 \mathrm{~m}$.

The observations were tested against the predictions of the linear wave theory, which we found to hold reasonably well, especially at higher levels above the ground. The profile of the squared vertical wavenumber revealed the presence of wave ducting conditions at levels below $\mathrm{z} \approx 350 \mathrm{~m}$. From the analysis of the different contributions to this profile, the Doppler ducting mechanism was identified as responsible for the long duration and spatial coverage of the event. The thermal stability had little effect, and the wave was ducted over the nose of a low-level jet opposed to the direction of wave propagation (i.e., a windspeed minimum as seen from the coordinate system of the wave).

Finally, multiresolution decomposition was applied to sonic anemometer data in order to obtain the contribution of the different scales to the total heat flux, kinetic energy and friction velocity, as well as to infer the spectral gap separating the turbulent contributions from the larger scales, in which waves can play an important role. Our analysis revealed an abrupt change in the turbulent regime during the passage of the wave packet along the experimental site. Turbulent motions decay as a result of the increase in thermal stability and decrease of wind shear during the event. The effect is more pronounced in purely dynamic turbulent parameters (friction velocity, kinetic energy). The heat flux cospectra, which are often used to determine the evolution of the gap separating turbulence from mesoscale motions, showed that the inhibition of turbulent motions did not affect the spectrum of heat transporting eddies homogeneously: the timescale of the mean eddies increased, and the overlapping with non-turbulent motions with a timescale of the order of the wave's period 
makes it impossible to define a reliable position of the spectral gap during the event.

These results highlight the need for special care when studying turbulent parameters in situations where a considerable interaction between waves and turbulence is produced. The traditional eddy covariance method based on fixed averaging windows cannot be used to evaluate parameters such as turbulent heat flux, friction velocity or turbulent kinetic energy, as these become clearly contaminated by larger scales that are not turbulent, resulting in completely unrealistic values of the turbulent quantities.

Acknowledgements The authors wish to thank Dr. Javier Peláez, from the CIBA, for his technical support and help through the SABLES2006 campaign. This research has been funded by the Spanish Ministry of Education and Science (projects CGL2004-03109 and CGL2006-12474-C03-03). IV PRICIT program (supported by CM and UCM) has also partially financed this work through the Research Group "Micrometeorology and Climate Variability" ( $\mathrm{n}^{\circ}$ 910437). We are also grateful to Prof. Casanova, Director of the CIBA, for his support and help.

\section{References}

Andrén A, Brown A R, Graf J, Mason P J, Moeng C-H, Nieuwstadt F T M and Schumann U (1994) Large-Eddy simulation of a neutrally stratifie boundary layer: A comparison of four computed ccodes. Quart J Roy Meteorol Soc 120:1457-1484.

Beare R J, MacVean M K, Holtslag A A M, Cuxart J, Esau I, Golaz J C, Jiménez M A, Khairoutdinov M, Kosovic B, Lewellen D, Lund T S, Lundquist J K, McCabe A, Moene A F, Noh Y, Raasch S, Sullivan P (2006) An intercomparison of large-eddy simulations of the stable boundary layer. Boundary-Layer Meteorol. 118:247-272.

Böhme T, Hauf T, Lehmann V (2004) Investigation of short-period gravity waves with the Lindenberg $482 \mathrm{MHz}$ tropospheric wind profiler. Quart J Roy Meterol Soc, 130:2933-2952 Bosart L F, Cussen Jr. J P (1973) Gravity wave phenomena accompanying East Coast cyclogenesis. Mon Wea Rev 101:446-454

Cheng Y, M B Parlange, W Brutsaert (2005) Pathology of Monin-Obukhov similarity in the stable boundary layer. J Geophys Res 110, D06101

Chimonas G, Hines C O (1986) Doppler ducting of atmospheric gravity waves. J Geophys Res 91(D1): 1219-1230

Chimonas G (1999) Steps, waves and turbulence in the stably stratified planetary boundary layer. Boundary-Layer Meteorol 90:397-421

Conangla L and Cuxart J (2006) On the turbulence in the upper part of the low-level jet: An experimental and numerical study Boundary-Layer Meteorol, 118:379-400.

Conangla L, Cuxart J, Soler M R (2008) On the turbulence in the upper part of the lowlevel jet: an experimental and numerical study. Boundary-Layer Meteorol 118:379-400

Cuxart J, Yagüe C, Morales G, Terradellas E, Orbe J, Calvo J, Fernández A, Soler M R, Infante C, Buenestado P, Espinalt A, Joergensen H E, Rees J M, Vil J, Redondo J M, Cantalapiedra I R, Conangla L (2000) Stable atmospheric boundary-layer experiment in Spain (SABLES98): A report. Boundary-Layer Meteorol 96:337-370

Cuxart J, Morales G, Terradellas E, Yagüe C (2002) Study of coherent structures and estimation of the pressure transport terms for the nocturnal stable boundary layer. BoundaryLayer Meteorol 105:305-328

Cuxart J, Jiménez M A (2007) Mixing processes in a nocturnal low-level jet: An LES study. J Atmos Sci 64:1666-1679.

Daubechies I (1992) Ten Lectures on Wavelets. Society for Industrial and Applied Mathematics, Philadelphia, PA, 354 pp

Drobinski P, Foster RC (2003) On the origin of near-surface streaks in the neutrally- 
stratified planetary boundary layer. Boundary-Layer Meteorol 108:247-256

Einaudi F, Finnigan J J (1981) The interaction between an internal gravity wave and the planetary boundary layer. Part I: The linear analysis. Quart J Roy Meteorol Soc 107: 793-806

Einaudi F, Finnigan J J (1993) Wave-Turbulence Dynamics in the Stably Stratified Boundary Layer. J Atmos Sci 50:1841-1864

Eom J K (1975) Analysis of the internal gravity wave occurrenceof 19 April 1970 in the Midwest. Mon Wea Rev 103:217-226

Farge M (1992) Wavelet transforms and their applications to turbulence. Annu Rev Fluid Mech 24:395-457

Finnigan J J, Einaudi F (1981) The interaction between an internal gravity wave and the planetary boundary layer. Part II: Effect of the wave on the turbulence structure. Quart J Roy Meteorol Soc 107:807-832

Finnigan J J, Einaudi F, Fua D (1984) The interaction between an internal gravity wave and turbulence in the stably-stratified nocturnal boundary layer. J Atmos Sci 41:24092436

Finnigan J J (1988) Kinetic energy transfer between internal gravity waves and turbulence. J Atmos Sci 45:486-505

Fritts D C, Nappo C, Riggin D M, Balsley B B, Eichenger W E, Newsom R (2003) Analysis of ducted motions in the stable nocturnal boundary layer during CASES-99. J Atmos Sci 60:2450-2472

Gossard E, Hooke W, Waves in the atmosphere. Elsevier, New York, 1975, 456pp

Howell J F, Mahrt L (1997) Multiresolution flux decomposition. Boundary-Layer Meteorol $83: 117-137$

Jiménez M A, Cuxart J (2005) Large-Eddy simulations of the stable boundary layer using the standard Kolmogorov theory: Range of applicability. Boundary-Layer Meteorol 115: 241-261.

Jones W L (1968a) Reflexion and stability of waves in stably stratified fluids with shear flow. J Fluid Mech 34:609-624

Jones W L (1968b) Ducting of internal gravity waves on a stable layer with shear. J Geophys Res 77:3879-3885

King J C M, Obbss D, Darbym S, Rees J M (1987) Observations of an internal gravity wave in the lower troposphere at Halley, Antarctica. Boundary-Layer Meteorol 39:1-13

Koch S E, Einaudi F, Dorian P B, Lang S, Heymsfield G M (1993) A mesoscale gravity wave event observed during CCOPE. Part IV: Stability analysis and Doppler-derived wave vertical structure. Mon Wea Rev 121:2483-2510

Koch S E, O'Handley C(1997) Operational forecasting and detection of mesoscale gravity waves. Wea Forecasting 12:253-281

Koch S E, Saleeby S (2001) An automated system for the analysis of gravity waves and other mesoscale phenomena. Wea Forecasting 16:661-679.

Lindzen, R S, Tung K K (1976) Banded convective activity and ducted gravity waves. Mon Wea Rev 104:1602-1617

Mahrt L, Vickers D (2006) Extremely weak mixing in stable conditions. Boundary-Layer Meteorol 119:19-39

Nappo C J, An Introduction to Atmospheric Gravity Waves. Academic Press, San Diego, 2002, 276pp

Nappo C J, Miller D R, Hiscox A L (2008) Wave-Modified Flux and Plume Dispersion in the Stable Boundary Layer. Boundary-Layer Meteorol 129:211-223

Pecnick M J, Young J A (1984) Mechanics of a strong subsynoptic gravity wave deduced from satellite and surface observations. J Atmos Sci 41:1850-1862

Ralph F M, Crochet M, Venkateswaran S V (1993) Observations of a mesoscale ducted gravity wave. J Atmos Sci 50:3277-3291

Rees J M, Staszewski W J, Winkler J R (2001) Case study of a wave event in the stable atmospheric boundary layer overlying an Antarctic Ice Shelf using the orthogonal wavelet transform. Dyn Atmos Oceans 34:245-261

San José R, Casanova J L, Viloria R E, Casanova J (1985) Evaluation of the turbulent parameters of the unstable surface boundary Layer outside Businger's range. Atmos Environ 19:1555-1461 
Smedman A-S, Bergström H, Högström U (1995) Spectra, variances and length scales in a marine stable boundary layer dominated by a low level jet. Boundary-Layer Meteorol $76: 211-232$

Sun J, Lenschow D H, Burns S P, Banta R, Newsom R, Coulter R, Frasier S, Ince T, Nappo C, Balsley B, Jensen M, Mahrt L, Miller D N, Skelly B T (2003) Atmospheric disturbances that generate intermittent turbulence in nocturnal boundary layers. Boundary-Layer Meteorol 110:255-279

Terradellas E, Morales G, Cuxart J, Yagüe C (2001) Wavelet methods: application to the study of the stable atmospheric boundary layer under non-stationary conditions. Dyn Atmos Oceans 34:225-244

Torrence C, Compo G P (1998) A practical guide to wavelet analysis. Bull Am Meteor Soc 79:61-78

Uccellini L W (1975) A case study of apparent gravity wave initiation of severe convective storms. Mon Wea Rev 103:497-513

Uccellini L W, Koch S E (1987) The synoptic setting and possible energy sources for mesoscale wave disturbances. Mon Wea Rev 115:721-729

Viana S, Yagüe C, Maqueda G, Morales G (2007) Study of the surface pressure fluctuations generated by waves and turbulence in the nocturnal boundary layer during SABLES2006 field campaign. Física de la Tierra 19:55-71 (available from http://revistas.ucm.es/fis/02144557/articulos/FITE0707110055A.PDF)

Viana S, Terradellas E, Yagüe C, Maqueda G (2008) Analysis of the different regimes of atmospheric turbulence observed during a single night. Nuovo Cimento C. Geophysics and Space Physics 31:723-742

Vickers D, Mahrt L (2003) The cospectral gap and turbulent flux calculations. J Atm Ocean Tech 20:660-672

Voronovich V, Kiely G (2007) On the gap in the spectra of surface-layer atmospheric turbulence, Boundary-Layer Meteorol 122:67-83

Wang T A, Lin Y L (1999) Wave ducting in a stratified shear flow over a two-dimensional mountain. Part I: General linear criteria. J Atmos Sci 56:412-436

Yagüe C, Cano J L (1994) Eddy transfer processes in the atmospheric boundary layer. Atmos Environ 28:1275-1289

Yagüe C, Viana S, Maqueda G, Lazcano M F, Morales G, Rees J M (2007) A study on the nocturnal atmospheric boundary layer: SABLES2006. Física de la Tierra 19:37-53 (available from http://revistas.ucm.es/fis/02144557/articulos/FITE0707110037A.PDF) 